\title{
Prevalence and associated factors of diarrhea among under-five children in Debre Berhan town, Ethiopia 2018: a cross sectional study
}

Sisay Shine ${ }^{1 *}$, Sindew Muhamud ${ }^{2}$, Solomon Adanew ${ }^{3}$, Alebachew Demelash ${ }^{2}$ and Makda Abate ${ }^{3}$

\begin{abstract}
Background: Diarrhea is responsible for 525,000 children under-five deaths and 1.7 billion cases globally and is the second leading cause of death among children under-five every year. It is a major public health problem in low income countries like Ethiopia. The main aim of this study was to assess the prevalence of diarrhea and associated risk factors among children under-five in Debre Berhan Town, Ethiopia.

Methods: A community-based cross-sectional study was conducted in 420 parent or caretaker/children pairs in Debre Berhan town between 13 and 18 April 2018. A multi-stage sampling strategy was used to select the study participants. Data were collected using pre-tested and structured questionnaires. Data were entered in Epi-info computer software version 3.5.1 and exported to SPSS Window Version-16 for analysis. Adjusted odds ratio with 95\% confidence intervals were used to assess the level of significance.

Results: The two week prevalence of diarrhea among children under-five was 16.4\% (69/351). Children aged 7-11 months (adjusted odds ratio (AOR): 4.2, 95\% confidence interval (Cl): 1.2-15.3), being the second-born child (AOR: 3.9, 95\%Cl: 1.8-8.5), not vaccinated against rotavirus (AOR: 10.3, 95\%Cl: 3.2-91.3) and feeding children by hand (AOR: 2.5, 95\%Cl: 1.1-6.1) were significant predictors of diarrhea.

Conclusions: This study revealed that the two weeks period prevalence of diarrhea among children under-five years was $16.4 \%$. Education programs on the importance of vaccination against rotavirus, increasing breast feeding frequency with complementary food after six months and the critical points of hand washing are recommended.
\end{abstract}

Keywords: Children, Diarrhea, Debre Berhan, Ethiopia

\section{Background}

Diarrheal disease is a major public health problem worldwide. Globally, 525,000 children under-5 years die due to diarrhea every year, roughly 2195 every day [1]. This represents $8 \%$ of all deaths and is the second leading cause of death among children under-5 years old [2]. Annually, 1.7 billion diarrhea episodes occurred among children under-5 years worldwide [3]. The majority of morbidity and mortality occurred in south Asia and subSaharan African countries, which $88 \%$ were attributable

\footnotetext{
* Correspondence: sisayask@gmail.com

${ }^{1}$ Public Health Department, College of Health Science, Debre Berhan

University, P.O.Box: 445, Debre Berhan, Ethiopia

Full list of author information is available at the end of the article
}

to unsafe water, inadequate sanitation, and insufficient hygiene [4].

Despite global diarrheal deaths among children of under 5 years decreasing by $60 \%$ between 2000 and 2017. Ethiopian morbidity reports and community-based studies indicate that diarrheal diseases accounted for $20 \%$ of childhood death and $22 \%$ of childhood diarrheal disease in $2000[3,5,6]$.

Studies in Ethiopia also showed that low maternal education, poor sanitation, contaminated water source, duration of breast feeding, failure to wash hands, absence of rotavirus vaccination, failure to dispose of feces hygienically, age of child and adequate food hygiene were

(c) The Author(s). 2020 Open Access This article is distributed under the terms of the Creative Commons Attribution 4.0 International License (http://creativecommons.org/licenses/by/4.0/), which permits unrestricted use, distribution, and reproduction in any medium, provided you give appropriate credit to the original author(s) and the source, provide a link to the Creative Commons license, and indicate if changes were made. The Creative Commons Public Domain Dedication waiver (http://creativecommons.org/publicdomain/zero/1.0/) applies to the data made available in this article, unless otherwise stated. 
significant predictors of diarrheal disease occurrence in children under-5 years [7-13].

However, information related to diarrheal disease in children under-five in Debre Berhan is limited. Therefore, the aim of this research was to assess the prevalence of diarrheal disease and associated factors in children under-5 years old in Debre Berhan town, Ethiopia. The findings will contribute to improving the lives of children under- 5 years. In addition, the information can be used to develop effective educational program to improve child health overall. Similarly, this research will inform policy makers and program initiators on acceptable services.

\section{Methods}

\section{Study area and period}

The study was conducted in Debre Berhan town from April 13-28, 2018. Debre Berhan town is found in North Showa Zone of Amhara regional state, around $130 \mathrm{~km}$ away from the capital of Ethiopia, Addis Ababa. It has one referral hospital, 3 health centers, 14 clinics and around 16 pharmacies. Based on the Debre Berhan town health administration office report, the current population of the town is 103,450 of whom 46,553 are men, 56,897 are women. From the total population, 14,011 are children under- 5 years.

\section{Study design}

A community-based cross-sectional study design was used to assess the prevalence of diarrhea and associated factors among children under- 5 years in Debre Berhan town.

\section{Study population}

All children under- 5 years old with their mothers or caretakers who live in selected kebeles of Debre Berhan town were our study population.

\section{Sample size determination}

Sample size was determined based on the formula used to estimate single population proportion, assuming 21.5\% 2 week period prevalence of diarrhea among children under-5 years [14], and a 5\% margin of error with 95\% confidence level. The sample size calculated was 256. After adjusting for a non-response rate of $10 \%$ and design effect of 1.5 the final sample size required was 428 mother/caretaker-child pairs.

\section{Sampling procedure}

Multi-stage sampling was used to obtain a representative sample of the study participants. Firstly, four kebeles were selected from the total fourteen kebeles using a lottery method. Then, a census was conducted in each of the selected kebeles to identify eligible households.
Finally, households were selected using systematic random sampling with a mother/caretaker-child pair selected from each household until the required sample size was fulfilled.

\section{Operational definitions \\ Diarrhea}

The passage of three or more loose or watery stool in a $24 \mathrm{~h}$ period, as reported by the mother/caretaker of the child [4].

\section{Caretaker}

Any person who provides care for the child other than the mother.

\section{Data collection tool and methods}

Data were collected by seven trained midwives and three supervisors. Structured questionnaires were developed in English after review of different literature and guidelines. English version questionnaires were translated into Amharic language and again translated back into English by experts fluent in both languages (Additional file 1). The training was given for data collectors and supervisors for 2 days on the study instrument and data collection procedures. Pre-testing was conducted on 5\% of the total sample size. Data were collected by face to face interview.

\section{Data processing and analysis}

The data collected from the field were edited, checked for completeness and consistency, coded and entered into Epi-info computer software version 3.5.1. Once entered, the data were exported to SPSS Window Version16 for cleaning and further analysis. Both descriptive and inferential statistics were employed in the analysis. Bivariate logistic regression analysis was performed for each independent variable with the outcome variable and those variables with a $p$-value of $<0.2$ included in multivariable logistic regression analysis to identify predictors of diarrhea. Enter method was used to select the variables in multivariate logistic regression analysis. Multicollinearity test was performed to assess the existence of correlation among the predictor variables. Additionally, goodness off fit to the final model was checked by Hosmer and Lemeshow and was found fit. Adjusted odds ratios with $95 \%$ confidence intervals were calculated and $P$-values less than 0.05 were considered statistically significant.

\section{Results}

\section{Socio-demographic characteristics of the mother/} caretaker and children

A total of 420 mother/caretaker completed the questionnaires. The majority $50.2 \%(211 / 420)$ of the mothers/caretakers were $20-29$ years of age with a mean age of 29.7 
years and SD of \pm 4.6 years. From the total study participants, $86.7 \%(364 / 420)$ were married and $83.6 \%(351 / 420)$ were orthodox religion. The majority $70.0 \%(294 / 420)$ of the household family size were between 1 and 4 people. Among the total respondents, 31.9\% (134/420) had a college education or additional qualification. More than half $55.5 \%(233 / 420)$ of the children were male and $21.2 \%$ (89/ 420 ) were $12-23$ months of age (Table 1 ).

\section{Environmental and hygiene characteristics}

In the study area, all of households have latrines in their dwellings. The majority $45.0 \%(189 / 420)$ of the households have traditional pit latrines and 61.9\% (260/420) dispose of the solid waste by private vendors. The majority $80.2 \%(337 / 420)$ dispose of children's feces in the

Table 1 Socio-demographic characteristics of mother/caretaker and children in Debre Berhan Town, Ethiopia 2018

\begin{tabular}{|c|c|c|}
\hline Variable & Frequency & Percent (\%) \\
\hline \multicolumn{3}{|c|}{ Relation of the respondent to the child } \\
\hline Mother & 387 & 92.1 \\
\hline Care taker & 33 & 7.9 \\
\hline \multicolumn{3}{|l|}{ Age of mother/caretaker } \\
\hline$<20$ & 13 & 3.1 \\
\hline $20-29$ & 211 & 50.2 \\
\hline $30-39$ & 175 & 41.7 \\
\hline$>=40$ & 21 & 5.0 \\
\hline \multicolumn{3}{|l|}{ Sex of children } \\
\hline Male & 233 & 55.5 \\
\hline Female & 187 & 44.5 \\
\hline \multicolumn{3}{|c|}{ Age of children (in months) } \\
\hline $0-6$ & 59 & 14.0 \\
\hline $7-11$ & 46 & 11.0 \\
\hline $12-23$ & 89 & 21.1 \\
\hline $24-35$ & 75 & 17.9 \\
\hline $36-47$ & 81 & 19.3 \\
\hline $48-59$ & 70 & 16.7 \\
\hline \multicolumn{3}{|c|}{ Educational status of mother/care taker } \\
\hline Can't read and write & 43 & 10.2 \\
\hline $1-4$ grade & 42 & 10.0 \\
\hline $5-8$ grade & 81 & 19.3 \\
\hline $9-12$ grade & 120 & 28.6 \\
\hline College and above & 134 & 31.9 \\
\hline \multicolumn{3}{|c|}{ Family size of the household } \\
\hline $1-4$ & 294 & 70.0 \\
\hline$>=5$ & 126 & 30.0 \\
\hline \multicolumn{3}{|c|}{ Household monthly income (Ethiopian Birr) } \\
\hline$<=3438$ & 247 & 58.8 \\
\hline$>3438$ & 173 & 41.2 \\
\hline
\end{tabular}

toilet. A further 57.6\% (242/420) dispose of household waste in the seepage pits and $80.2 \%(337 / 420)$ of households get their water from a pipe (Table 2).

\section{Health and dietary characteristics of children}

From the study participants, 50.0\% (210/420) of children under-five were the first-born of their family. About, 90.7\% (381/420) of the children were born in health institutions. The majority $71.2 \%$ (299/420) of children under-five started complementary feeding at 6 months of age. About, $79.5 \%(334 / 420)$ of children were vaccinated against measles and $96.0 \%(403 / 420)$ against rotavirus (Table 3).

Prevalence of diarrhea among children under-five years The prevalence of diarrhea among children under-five was reported to be $16.4 \%$ [95\%CI: $12.7-20.0$ ] in the 2

Table 2 Environmental characteristics of household in Debre Berhan town, Ethiopia, 2018

\begin{tabular}{|c|c|c|}
\hline Variable & Frequency & Percent \\
\hline \multicolumn{3}{|l|}{ Type of latrine used by households } \\
\hline Traditional pit latrine & 189 & 45.0 \\
\hline Ventilated improved pit latrine & 107 & 25.5 \\
\hline Shared latrine & 84 & 20.0 \\
\hline Flush latrine & 40 & 9.5 \\
\hline \multicolumn{3}{|l|}{ Solid waste disposal methods } \\
\hline Privately prepared pit hole & 20 & 4.8 \\
\hline Burning & 93 & 22.1 \\
\hline Collected by private vendors & 260 & 61.9 \\
\hline Dumped in street & 47 & 11.2 \\
\hline \multicolumn{3}{|l|}{ Liquid waste disposal methods } \\
\hline Septic tank & 54 & 12.9 \\
\hline Seepage pit & 242 & 57.6 \\
\hline Open surface & 124 & 29.5 \\
\hline \multicolumn{3}{|l|}{ Children's feces disposal methods } \\
\hline Toilet & 337 & 80.2 \\
\hline Covered by soil & 49 & 11.7 \\
\hline Open space & 34 & 8.1 \\
\hline \multicolumn{3}{|l|}{ Source of water } \\
\hline Unprotected spring & 40 & 9.5 \\
\hline Piped & 337 & 80.2 \\
\hline Protected spring & 43 & 10.3 \\
\hline \multicolumn{3}{|l|}{ Distance of water source to home } \\
\hline$<15 \min$ & 388 & 92.4 \\
\hline$>=15 \min$ & 32 & 7.6 \\
\hline \multicolumn{3}{|l|}{ Hand washing facility beside toilets } \\
\hline Yes & 178 & 42.4 \\
\hline No & 242 & 57.6 \\
\hline
\end{tabular}


Table 3 Health and dietary characteristics of children under-five in Debre Berhan Town, Ethiopia 2018

\begin{tabular}{lll}
\hline Variable & Frequency & Percent \\
\hline Birth order & 210 & 50.0 \\
First & 121 & 28.8 \\
Second & 49 & 11.7 \\
Third & 40 & 9.5 \\
Fourth and above & & \\
Place of delivery & 39 & 9.3 \\
Home & 381 & 90.7 \\
Health institution & & \\
Duration of breast feeding & 244 & 59.8 \\
0-23 months & 61 & 15.0 \\
24 months & 103 & 25.2 \\
>=25 & & \\
Got rotavirus vaccination & 403 & 96.0 \\
Yes & 17 & 4.0 \\
No & & 7.9 \\
Got measles vaccination & 334 & 20.9 \\
Yes & 86 & 79.5 \\
No & & \\
Complementary food started & & \\
At 6 month & & \\
Before 6 month & & \\
After six month & 33 & \\
\hline
\end{tabular}

week surveillance period, of whom $8.6 \%$ (36/420) were males. Among children who had diarrhea, 15.9\% (67/ 420) experienced watery diarrhea with a few reporting bloody or mucoid stools. The prevalence of diarrhea was $2.6 \%(11 / 420)$ in children aged 7-11 months (Table 4).

\section{Factors associated with diarrhea among children under- five years}

In the bivariate analysis, age of child, birth order, age of starting complementary food, vaccination against rotavirus and feeding children by hand were significantly associated with diarrhea (Table 4). The results from multivariate logistic regression analysis revealed the odds of developing diarrhea among children in the age group 7-11 months were 4.2 times higher (AOR: $4.2,95 \% \mathrm{CI}$ : $1.2-15.3)$ compared to the $48-59$ month age group. Being the first-born (AOR: 3.9, 95\%CI: 1.8-8.5), unvaccinated against rotavirus (AOR: 10.3, 95\%CI: 3.2-91.3) and hand-feeding of child (AOR: 2.5, 95CI: 1.1-6.1) were significant predictors of diarrhea (Table 4).

\section{Discussion}

This study was conducted to assess the prevalence and associated factors of diarrhea among children under-five in Debre Berhan town, Ethiopia. The Ethiopian Demographic and Health Surveys of 2016, showed that

Table 4 Bivariate and multivariate analysis on determinants of under-five diarrhea in Debre Berhan Referral Hospital, Ethiopia 2018

\begin{tabular}{|c|c|c|c|c|}
\hline \multirow[t]{2}{*}{ Variables } & \multicolumn{2}{|c|}{ Diarrheal status of child } & \multirow[t]{2}{*}{ COR $(95 \% \mathrm{Cl})$} & \multirow[t]{2}{*}{ AOR $(95 \% \mathrm{Cl})$} \\
\hline & Yes & No & & \\
\hline \multicolumn{5}{|c|}{ Age of children (in months) } \\
\hline $0-6$ & $6(1.4)$ & $53(12.6)$ & $1.2(0.6-8.2)$ & $0.3(0.1-16.2)$ \\
\hline $7-11$ & $11(2.6)$ & $35(8.3)$ & $1.9(0.7-5.3)$ & $4.2(1.2-15.3)^{*}$ \\
\hline $12-23$ & $16(3.8)$ & $73(17.4)$ & $1.3(0.8-6.1)$ & $0.9(0.3-3.0)$ \\
\hline 24-35 & $15(3.6)$ & $60(14.3)$ & $1.5(0.5-4.0)$ & $1.1(0.3-3.5)$ \\
\hline $36-47$ & $11(2.6)$ & $70(16.7)$ & $0.9(0.5-4.3)$ & $0.4(0.2-1.7)$ \\
\hline $48-59$ & $10(2.4)$ & $60(14.3)$ & 1.0 & 1.0 \\
\hline \multicolumn{5}{|l|}{ Birth order of children } \\
\hline First & $28(6.7)$ & $182(43.3)$ & 1.0 & 1.0 \\
\hline Second & $28(6.7)$ & $93(22.1)$ & $2.0(1.2-3.1)$ & $3.9(1.8-8.5)^{*}$ \\
\hline Third & $3(0.7)$ & $46(11.0)$ & $0.4(0.2-2.1)$ & $0.2(0.1-1.3)$ \\
\hline Fourth and above & $10(2.3)$ & $30(7.2)$ & $2.2(0.1-4.8)$ & $1.4(0.4-5.1)$ \\
\hline \multicolumn{5}{|l|}{ Weaning age of children } \\
\hline At six month & $50(11.9)$ & $249(59.3)$ & 1.0 & 1.0 \\
\hline Less than six month & $10(2.4)$ & $43(10.2)$ & $1.2(0.2-2.2)$ & $0.6(0.1-1.8)$ \\
\hline Above six month & $9(2.1)$ & $59(14.1)$ & $0.8(0.1-1.1)$ & $0.2(0.1-1.4)$ \\
\hline \multicolumn{5}{|l|}{ Rotavirus vaccination } \\
\hline Yes & $62(14.7)$ & $341(81.2)$ & 1.0 & 1.0 \\
\hline No & $7(1.7)$ & $10(2.4)$ & $3.6(1.4-10.5)$ & $10.3(3.2-91.3)^{*}$ \\
\hline \multicolumn{5}{|c|}{ Feeding child by using hand } \\
\hline Yes & $32(7.6)$ & $133(31.7)$ & $1.4(1.2-3.1)$ & $2.5(1.1-6.1)^{*}$ \\
\hline No & $37(8.8)$ & $218(51.9)$ & 1.0 & 1.0 \\
\hline
\end{tabular}

*Significant at $P<0.05$ 
diarrheal disease was the leading cause of illness among children under- 5 years.

The result of this study showed that prevalence of diarrhea among children under-five was 16.4\% (95\%CI: 12.7-20.0). This finding was congruent with the study done in Dale District, Sidama zone, Southern Ethiopia, 13.9\% [11], Yaya Gulele district, Ethiopia 13.5\% [15], Serbo town, Southwest, Ethiopia, 14.9\% [16], Bahr Dar city, 14.5\% [17], and Farta Wereda, Northwest Ethiopia, $16.7 \%$ [7]. However, result of this study was lower than the study conducted in Sena'a, Yemen, 29.07\% [18], Senegal, 26\% [19], Cameroon, 26.1\% [20], Sheka zone, southwest Ethiopia, 21.8\% [12], Jig-Jiga city, Eastern Ethiopia, 27.3\% [21], Bahir Dar Zuria district, Northwest Ethiopia, 20\% [22], North Gondar zone, 21.1\% [10] and Harena Buluk district, Southeast Ethiopia, 28.4\% [23]. In contrast, it was higher than the study conducted in Wolayta Sodo town, Southern Ethiopia, 11.0\% [24]. This difference may be due to seasonal trends in diarrhea disease or differences in year and age of the study participants as well as the differences in the study design and data collection.

Children aged between 7 and 11 months were at high risk of developing diarrhea compared with children aged was less than 7 months. This result was in line with the results of the study conducted in Farta Wereda, Northwest Ethiopia [7]. The increased risk might be due to the decline/loss in maternal antibodies and at this age child start complementary feeding that might increase their exposure to contaminated foods and water. In addition, crawling begins at this age further increasing potential exposure to fecally contaminated environments.

This study found that diarrhea was more common among second-born children compared with first-born children (AOR: 3.9, 95\%CI: 1.7-8.5). Similarly, a crosssectional study conducted in Jig-Jiga district, Somali region, Ethiopia showed that fourth-born children and above were more affected by diarrhea compared with first borne [21]. This may be due to quality of care and attention from parents decreases as mothers become incapable of caring for children [25].

According rotavirus vaccination were 10.3 times more likely to have diarrhea compared with children who received rotavirus vaccination (AOR: 10.3, 95\%CI: $1.2-$ 91.2). The result suggests that a major contributor to the diarrheal burden in children less than 5 years in the town is in fact rotavirus. This result was in agreement with study done in Farta Woreda, Northwest Ethiopia [7].

In this study, the following limitations were noted. The major limitation of the study was the limited time period over which the study was conducted, that may create over or under reporting of diarrhea since diarrheal diseases have some seasonal variations.

\section{Conclusions}

The 2 week prevalence of diarrhea among children under-5 years in Debre Berhan town was $16.4 \%$. Childhood diarrheal disease was significantly associated with the age of children, birth order and hand feeding practice of mother. So, education program on the importance of vaccination against rotavirus, increase breast feeding frequency with complementary food after 6 months and the critical points of hand washing are recommended.

\section{Supplementary information}

Supplementary information accompanies this paper at https://doi.org/10 1186/s12879-020-4905-3.

Additional file 1. Questionnaire on Diarrheal study

Abbreviations

AOR: Adjusted odd ratio; BSc: Bachelors of science; Cl: Confidence interval; SD: Standard deviation

\section{Acknowledgements}

We would like to thank town administrative health office heads for their collaboration during conducting this research. At last but not least, we would like to forward our special thank and sincere appreciations to our friends who gave advice and comment throughout the whole research project activities.

\section{Authors' contributions}

SS, SM, SA, AD and MA: have contribution in the study protocol design development, data collection, data quality monitoring, data analysis and preparation of the manuscript. All authors read and approved the final manuscript.

\section{Funding}

Not applicable.

\section{Availability of data and materials}

The datasets used and/or analyzed during the current study available from the corresponding authors on reasonable request.

\section{Ethics approval and consent to participate}

This study was carried out after getting ethical clearance from Debre Berhan University research ethics review committee and from Debre Berhan town administrative health bureau. Because, we did not report individual research participants' data. Mothers'/caretakers were briefed verbally about objective and importance of the study and required to sign consent forms. The confidentiality of information was kept during and after the interview by using codes rather than participants' name. Participation was voluntary and could be withdrawn at any time point without negative consequences for the participants.

\section{Consent for publication}

Not applicable.

\section{Competing interests}

The Authors declare that we do not have any financial or non-financial competing interests in reference to this article for its publication.

\section{Author details}

${ }^{1}$ Public Health Department, College of Health Science, Debre Berhan University, P.O.Box: 445, Debre Berhan, Ethiopia. ${ }^{2}$ Nursing Department, College of Health Science, Debre Berhan University, Debre Berhan, Ethiopia. ${ }^{3}$ Midwifery Department, College of Health Science, Debre Berhan University, Debre Berhan, Ethiopia. 
Received: 5 August 2019 Accepted: 18 February 2020

Published online: 24 February 2020

\section{References}

1. UNICEF: Diarrhea remains a leading killer of young children, despite the availability of simple treatment solution, updated. 2016: UNICEF.org/childhealth/ diarrheal disease.html.

2. UNICEF. One is too many; ending child death from pnemonia and diarrhea New York, NY 10017. USA: Lancet; 2016.

3. UNICEF: Monitoring the situation of children and women 2019: https://data. unicef.org/topic/child-health/diarrhoeal-disease/.

4. WHO: Diarrhoeal disease. 2017:https://www.who.int/news-room/fact-sheets/ detail/diarrhoeal-disease.

5. Ministry of Finance and Economic Development Ethiopia: MDGs report: trends and Prospects in meeting MDGs in 2015 Addis Ababa: Federal Ministry of Finance and Economic Development 2010.

6. Alebel A, Tesema C, Temesgen B, Gebrie A, Petrucka P, Kibret GD Prevalence and determinants of diarrhea among under-five children in Ethiopia: Asystematic review and meta-analysis. PLoS One 2018, 13(6): e0199684: https://doi.org/0199610.0191371/jornal.pone.0199684.

7. Gedamu G, Kumie A, Haftu D. Magnitude and associated factors of diarrhea among under five children in Farta Wereda, north West Ethiopia. Qual Prim Care. 2017;25(4):199-207.

8. Gunsa GG, Rodamo KM, Dangiso DD. Determinants of acute Diarrhoea among children aged 6-59 months in Chire District, Southern Ethiopia: Unmatched Case-Control Study. J Gynecol Obstet. 2018;6(2):15-25.

9. Kasye DG, Garoma NH, Kassa MA. Assessments of prevalence of diarrhea disease under-five children Serbo town, Jimma zone south west, Ethiopia. Clin Mother Child Health. 2018;15:281

10. Getachew A, Guadu T, Tadie A, Gizaw Z, Gebrehiwot M, Hailecherkos D, Menberu MA, Gebrecherkos T. Diarrhea prevalence and Sociodemographic factors among under-five Childrenin rural areas of North Gondar zone, Northwest Ethiopia. Int J Pediatr. 2018;2018.

11. Melese B, Paulos W, Astawesegn FH, Gelgelu TB. Prevalence of diarrheal diseases and associated factors among under-five children in Dale District, Sidama zone, Southern Ethiopia: a cross-sectional study. BMC Public Health. 2019;19:1235.

12. Gashaw TA, Walie YM. Prevalence and determinate factors of diarrhea morbidity among under-five children in shake zone, Southwest Ethiopia, a community based cross-sectional study. Arch Community Med Public Health. 2019;5(1):008-14.

13. Mengistie B, Mesfin F, Argaw R, Getachew B. Factors associated with acute diarrhea among children aged 0-59 months in Harar town, eastern Ethiopia. East Afr J Health Biomed Sci. 2018;2(1):26-35.

14. Anteneh ZA, Andargie K, Tarekegn M. Prevalence and determinants of acute diarrhea among children younger than five years old in Jabithennan District, Northwest Ethiopia 2014. BMC Public Health. 2017;17:99.

15. Degabasa MZ, Weldemichael DZ, Marama MT. Diarrheal status and associated factors in under five years old children in relation to implemented and unimplemented community lead total sanitation and hygiene in Yaya Gulele in 2017. Pediat Health, Med Ther. 2018;9:109-21.

16. Kasee LF, Merrom OS, Hassa HY. Assessments of the prevalence of diarrhea disease under-five children Serbo town, Jimma Zone Southwest Ethiopia. Clin Mother Child Health. 2018:15:281

17. Dagnew AB, Tewabe T, Miskir Y, Eshetu T, Kefelegn W, Zerihun K, Urgessa M, Teka T. Prevalence of diarrhea and associated factors among under-five children in Bahir Dar city, Northwest Ethiopia, 2016: across-sectional study. BMC Infect Dis. 2019;19:417.

18. Mohanna MA, Al-Sonboli N. Prevalence ofdiarrhoea and related risk factors among children aged under 5 years in Sana'a, Yemen. Hamdan Med J. 2018;11:29-33.

19. Sokhna T, Aminata N, Samuel F, Mirko S, Ibrahima S, Jacques A. Prevalence of diarrhea and risk factors among children under five years old in mbour, Senegal. Infect Dis Poverty. 2017;6:109.

20. Tambe BA, Nyobe EC, Nchung JA, Ndzana AC, Essa'a VJ, Baleba MR, Medoua GN, Dapi NL. Prevalence of diarrhoea and associated risk factors health district- Cameroon, sub-Saharan Africa. MOJ Public Health. 2018;7(6):259-64.

21. Hashi A, Kumie A, Gasana J. Prevalence of Diarrhoea and associated factors among under-five children in Jigjiga District, Somali region, Eastern Ethiopia Open. Prev Med. 2016;6:233-46.
22. Asnakew DT, Teklu MG, Woreta SA. Prevalence of diarrhea among underfive children in health extension model households in Bahir Dar Zuria district, North-Western Ethiopia. Edorium J Public Health. 2017;4:1-9.

23. Beyene SG, Melku AT. Prevalence of diarrhea and associated factors among under five years children in Harena Buluk Woreda Oromia region, Southeast Ethiopia, 2018. J Public Health International. 2018;1(2):1-9.

24. Alambo KA. The Prevalence of Diarrheal Disease in under Five Children and associated Risk Factors in Wolitta Soddo Town, Southern, Ethiopia. ABC Research Alert. 2015:3(2).

25. Mihrete TS, Alemie GA, Teferra AS. Determinants of childhood diarrhea among under five children in Benishangul Gumuz regional state, North West Ethiopia. BMC Pediatr. 2014;14:1

\section{Publisher's Note}

Springer Nature remains neutral with regard to jurisdictional claims in published maps and institutional affiliations.
Ready to submit your research? Choose BMC and benefit from:

- fast, convenient online submission

- thorough peer review by experienced researchers in your field

- rapid publication on acceptance

- support for research data, including large and complex data types

- gold Open Access which fosters wider collaboration and increased citations

- maximum visibility for your research: over $100 \mathrm{M}$ website views per year

At BMC, research is always in progress.

Learn more biomedcentral.com/submissions 